\title{
Relationships of surface air temperature anomalies over Europe to persistence of atmospheric circulation patterns conducive to heat waves
}

\author{
J. Kyselý and R. Huth \\ Institute of Atmospheric Physics AS CR, Prague, Czech Republic \\ Received: 31 May 2007 - Revised: 27 December 2007 - Accepted: 28 December 2007 - Published: 10 April 2008
}

\begin{abstract}
Heat waves are among natural hazards with the most severe consequences for human society, including pronounced mortality impacts in mid-latitudes. Recent studies have hypothesized that the enhanced persistence of atmospheric circulation may affect surface climatic extremes, mainly the frequency and severity of heat waves. In this paper we examine relationships between the persistence of the Hess-Brezowsky circulation types conducive to summer heat waves and air temperature anomalies at stations over most of the European continent. We also evaluate differences between temperature anomalies during late and early stages of warm circulation types in all seasons. Results show that more persistent circulation patterns tend to enhance the severity of heat waves and support more pronounced temperature anomalies. Recent sharply rising trends in positive temperature extremes over Europe may be related to the greater persistence of the circulation types, and if similar changes towards enhanced persistence affect other mid-latitudinal regions, analogous consequences and implications for temperature extremes may be expected.
\end{abstract}

\section{Introduction}

Extreme temperature events affect a number of sectors of human activities, with enormous socio-economic impacts. In most mid-latitudinal regions, including the U.S. and Europe, mean annual numbers of deaths due to heat waves are largest among all natural hazards, and heat waves are most deadly of all atmospheric hazards on the global scale (e.g. Sheridan and Kalkstein, 2004; Poumadere et al., 2006). Both large temperature changes due to annual cycle and high withinseason variability of weather cause that populations living in mid-latitudes are particularly prone to heat-related mortal-

Correspondence to: J. Kyselý

(kysely@ufa.cas.cz) ity. Rising trends in the frequency and severity of heat waves have recently been observed in many areas, and there is a concern that these trends are likely to continue towards future due to global climate change. Improved understanding of meteorological causes and present and future probabilities of such extremes is essential, among others, in deciding on measures that need to be adopted to mitigate future negative impacts of hot summer weather.

Variability of surface meteorological variables, including air temperature and extreme temperature events, is primarily governed by atmospheric circulation. The recent occurrence of long and severe heat waves over western and central Europe (in August 2003 and July 2006), associated with enormous mortality impacts (e.g. Grize et al., 2005; Filleul et al., 2006; Poumadere et al., 2006) and other adverse effects, was related to persistent circulation patterns supporting positive anomalies of surface air temperature and influencing a large area over prolonged time periods.

The persistence of the atmospheric circulation, measured by mean residence times of the Hess-Brezowsky circulation types (Hess and Brezowsky, 1952), has significantly increased over Europe since the mid-1980s in all seasons and for most groups of weather types (Werner et al., 2000; Kyselý, 2002; Kyselý and Domonkos, 2006). Since steady circulation conditions usually support spells of either positive or negative temperature anomalies, a greater persistence may affect the occurrence of surface climatic extremes, particularly heat waves (demonstrated by Kyselý, 2007 for temperature anomalies at the Prague station). For this reason, the observed rising trends in high-temperature extremes over Europe and their more frequent and severe occurrence in the 1990s and early 2000s (e.g. Domonkos et al., 2003; Beniston, 2004; Schär et al., 2004; Moberg and Jones, 2005) may be related to the enhanced persistence of the atmospheric circulation.

Published by Copernicus Publications on behalf of the European Geosciences Union. 


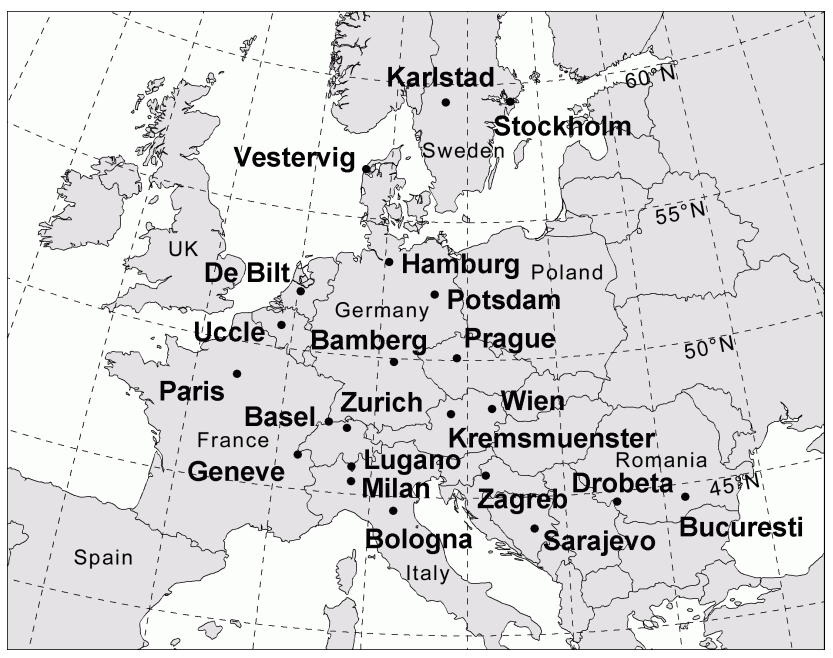

Fig. 1. Locations of stations used in the analysis.

This study identifies relationships of surface air temperature anomalies over Europe to the persistence of circulation patterns conducive to heat waves, and demonstrates the consequences that changes in the residence times of circulation types may have on the occurrence of heat waves (in summer) and positive temperature anomalies generally (in all seasons).

\section{Data and methods}

\subsection{Temperature series}

Long-term series of daily mean temperature (TAVG) from stations with continuous air temperature measurements over the 20th century are examined (Table 1, Fig. 1). They were obtained from the European Climate Assessment (ECA) dataset (Klein Tank et al., 2002; Wijngaard et al., 2003), the IMPROVE project (Camuffo and Jones, 2002) and MeteoSwiss (Begert et al., 2005); more details concerning their reliability and homogeneity can be found in the references cited. Anomalies of TAVG from the mean annual cycle (smoothed by 7-day running means) were computed at each station and are examined.

\subsection{Heat waves}

The definition utilized herein is the same as in Kyselý and Dubrovský (2005) and Kyselý (2007). It is based on percentiles of the empirical distributions of deviations of TAVG from the mean annual cycle $\left(\mathrm{M}_{\mathrm{TAVG}, \mathrm{d}}\right)$, owing to the fact that the relationship to circulation patterns is more straightforward for temperature anomalies than temperature itself. Heat waves are examined as periods of at least 3 successive days with TAVG-M $\mathrm{MAVG}_{\mathrm{TA}, \mathrm{d}}$ reaching or exceeding the longterm 95th percentile on day $d(d=1, \ldots 365)$ of the empirical distribution function of TAVG-M $\mathrm{MAVG}_{\mathrm{TA}, \mathrm{d}}$ over a 61-day interval $<\mathrm{d}-30, \mathrm{~d}+30>$ and all years with TAVG data at a given station.

The analysis is carried out for summer season (JJA) and covers the period 1901-2000. The average duration of heat waves ranges from 3.8 to 4.5 days, and the longest spells over the 20th century last between 9 and 19 days at individual sites.

\subsection{Circulation types}

The Hess-Brezowsky catalogue of large-scale circulation patterns (Hess and Brezowsky, 1952; Gerstengarbe et al., 1999) describes the atmospheric flow over most of Europe. It is frequently applied in examining relations between circulation types and surface climatic variables over many regions in Europe. The classification recognizes 29 types (Grosswetterlagen); each occurrence of any type persists for at least 3 days, the mean residence times (over 1881-2000) being between 4.3 and 6.2 days. For the description of the types as well as for details on the classification see e.g. Gerstengarbe et al. (1999); mean maps of the types are available on-line from Cawley (2002). The catalogue extends back to 1881 . Links to temperature anomalies are analyzed for individual circulation types (denoted CT hereafter).

2.4 Identification of circulation types conducive to heat waves and statistical testing for differences in means

The link between a CT and heat waves is evaluated in terms of an efficiency coefficient defined as a ratio of a relative frequency of a given CT in heat waves to its long-term mean frequency in JJA (cf. Kyselý, 2007). A CT tends to be conducive to heat waves if the efficiency coefficient is higher than 1.0. The ratios are tested for their statistical significance using a block resampling method in which sequences of days classified with one CT (in JJA) were taken as blocks. The null hypothesis is that the efficiency coefficient is not higher than 1.0. The tests are evaluated at the significance level $\mathrm{p}=0.05$ by means of 1000 artificial series of CTs, created by random reshuffling of the blocks (sequences of days classified with one CT) from the original series of CTs in JJA over 1901-2000.

Average TAVG anomalies at individual stations are examined on early (days 1-5) and late stages (days $>5$ ) of CTs, separately for each CT significantly conducive to heat waves, in order to depict the influence of persistent circulation patterns on air temperature. The Wilcoxon rank-sum test is employed for testing differences between means of air temperature anomalies on the late and early stages of the CTs, and it is evaluated at $\mathrm{p}=0.05$ against the null-hypothesis that there is no difference between the means. 
Table 1. Long-term European stations used in the analysis. The stations are grouped by countries. ECA: European Climate Assessment Project; CJ: Camuffo and Jones (2002).

\begin{tabular}{llccc}
\hline station & country & elevation [ma.s.1.] & period examined & source \\
\hline Paris-Montsouris & France & 75 & $1901-2000$ & ECA \\
Uccle & Belgium & 100 & $1901-1999$ & CJ, ECA \\
De Bilt & Netherlands & 2 & $1901-2000$ & ECA \\
Geneve & Switzerland & 420 & $1901-2000$ & MeteoSwiss \\
Basel & Switzerland & 316 & $1901-2000$ & MeteoSwiss \\
Zurich & Switzerland & 556 & $1901-2000$ & MeteoSwiss \\
Lugano & Switzerland & 273 & $1901-2000$ & MeteoSwiss \\
Milan & Italy & 122 & $1901-1998$ & CJ \\
Bologna & Italy & 60 & $1901-2000$ & ECA \\
Hamburg-Bergedorf & Germany & 35 & $1901-2000$ & ECA \\
Bamberg & Germany & 282 & $1901-2000$ & ECA \\
Potsdam & Germany & 81 & $1901-2000$ & ECA \\
Vestervig & Denmark & 18 & $1901-1999$ & ECA \\
Karlstad & Sweden & 46 & $1918-2000$ & ECA \\
Stockholm & Sweden & 44 & $1901-2000$ & CJ \\
Prague-Klementinum & Czech Republic & 197 & $1901-2000$ & ECA \\
Kremsmünster & Austria & 383 & $1901-1998$ & ECA \\
Wien & Austria & 199 & $1901-2000$ & ECA \\
Zagreb & Croatia & 157 & $1901-1997$ & ECA \\
Sarajevo & Bosnia-Herzegovina & 577 & $1901-1999$ & ECA \\
Drobeta & Romania & 77 & $1930-1993$ & ECA \\
Bucuresti & Romania & 90 & $1930-1993$ & ECA \\
\hline
\end{tabular}

\section{Results}

\subsection{Circulation types conducive to heat waves}

Central-European high types (HM, BM), east types anticyclonic over central Europe (HFA, HNFA) and south types (SWZ, SEA, TRW) are involved most frequently among CTs significantly conducive to heat waves in JJA at individual stations. The efficiency coefficients (Table 2) reach values up to 10 for some CTs; large differences between mean long-term seasonal frequencies of the CTs and their frequencies in heat waves are demonstrated in Fig. 2 for Bamberg, Germany.

Prevailing positive radiative balance due to small cloud cover under a dominant high pressure system influence and/or a warm air-mass advection from the southwest to east is typical for the CTs conducive to heat waves (cf. on-line mean charts of individual CTs in Cawley, 2002). The influence of the central-European high and east types is smallest in the south and southeast where the south types are associated with large values of the efficiency coefficient. Due to a warm advection on the rear of central-European highs, the coefficients for HM are largest in western Europe. Mean temperature anomalies in individual CTs appear to be more uniform in regions that are relatively far from areas on which the classification puts emphasis (western and central Europe around $\left.50^{\circ} \mathrm{N}\right)$.

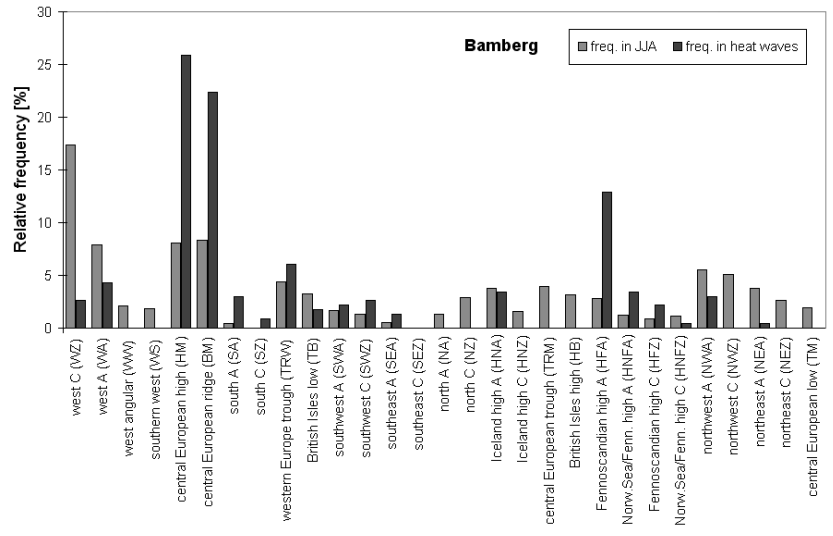

Fig. 2. Mean relative frequencies of circulation types (CTs) in JJA and in heat waves in Bamberg (Germany). A (C) denotes anticyclonic (cyclonic) CTs.

3.2 Differences between average temperature anomalies during late and early stages of CTs conducive to heat waves

Average TAVG anomalies observed during late (days $>5$ ) and early stages (days 1-5) of sequences classified with the same CT were computed, and the significance of their difference was assessed by means of the rank-sum test (Sect. 2.4). 
Table 2. Efficiency coefficients of circulation types (CTs) significantly conducive to heat waves in JJA $\left(c_{e f}\right)$, and differences between average anomalies of TAVG during late (days $>5$ ) and early stages (days 1-5) of sequences classified with a given CT ( $\left.T_{\text {diff }}\right)$. Only data for CTs significantly conducive to heat waves are shown; CTs with the mean seasonal frequency below $0.5 \%$ are omitted. Symbol $*$ denotes $T_{\text {diff }}$ significantly different from zero at the 0.05 level.

\begin{tabular}{|c|c|c|c|c|c|c|c|c|c|c|c|c|c|c|c|c|c|c|}
\hline \multirow[b]{2}{*}{ station } & & \multicolumn{2}{|c|}{$\begin{array}{c}\text { central European } \\
\text { high }\end{array}$} & \multicolumn{4}{|c|}{ east } & \multicolumn{5}{|c|}{ south } & \multicolumn{2}{|c|}{ northeast } & \multicolumn{4}{|c|}{ other } \\
\hline & & HM & BM & HFA & HNFA & HFZ & HNFZ & TRW & SWA & SWZ & SEA & TB & NEA & NEZ & WA & NWA & HNA & TRM \\
\hline \multirow[t]{2}{*}{ Paris } & $c_{e f}$ & 4.08 & 2.35 & 6.28 & 3.29 & & & & & & & & & & & & 2.44 & \\
\hline & $T_{\text {diff }}\left[{ }^{\circ} \mathrm{C}\right]$ & $2.16^{*}$ & $0.49^{*}$ & 0.43 & -0.64 & & & & & & & & & & & & 0.20 & \\
\hline \multirow[t]{2}{*}{ Uccle } & $c_{e f}$ & 4.65 & 2.30 & 5.20 & 4.57 & & & & & & & & & & & & 2.19 & \\
\hline & $T_{\text {diff }}\left[{ }^{\circ} \mathrm{C}\right]$ & $2.75^{*}$ & 0.27 & 0.58 & -1.01 & & & & & & & & & & & & 0.03 & \\
\hline \multirow[t]{2}{*}{ De Bilt } & $c_{e f}$ & 3.70 & & 7.50 & 9.53 & & & & & & 5.00 & & 2.14 & & & & 2.27 & \\
\hline & $T_{\text {diff }}\left[{ }^{\circ} \mathrm{C}\right]$ & $2.36^{*}$ & & 0.60 & 0.16 & & & & & & 1.49 & & 0.39 & & & & 0.18 & \\
\hline \multirow[t]{2}{*}{ Geneve } & $c_{e f}$ & 3.10 & & & & & & & & 3.79 & 4.45 & & & & & & & \\
\hline & $T_{\text {diff }}\left[{ }^{\circ} \mathrm{C}\right]$ & $2.32 *$ & & & & & & & & $-1.63^{*}$ & -1.63 & & & & & & & \\
\hline \multirow[t]{2}{*}{ Basel } & $c_{e f}$ & 3.43 & 2.11 & 3.19 & & & & & 3.70 & & & & & & & & & \\
\hline & $T_{\text {diff }}\left[{ }^{\circ} \mathrm{C}\right]$ & $2.71 *$ & $0.89^{*}$ & 0.07 & & & & & -0.08 & & & & & & & & & \\
\hline \multirow[t]{2}{*}{ Zurich } & $c_{e f}$ & 3.48 & 2.52 & 3.79 & & & & & & 4.16 & 6.40 & & & & & & & \\
\hline & $T_{\text {diff }}\left[{ }^{\circ} \mathrm{C}\right]$ & $2.80 *$ & $0.99^{*}$ & 0.04 & & & & & & $-1.96^{*}$ & -5.10 & & & & & & & \\
\hline \multirow[t]{2}{*}{ Lugano } & $c_{e f}$ & 1.98 & 2.24 & & & & & & & & 5.33 & & & & 2.43 & 2.10 & & \\
\hline & $T_{\text {diff }}\left[{ }^{\circ} \mathrm{C}\right]$ & $1.72 *$ & $0.86^{*}$ & & & & & & & & -1.78 & & & & $0.74 *$ & -0.10 & & \\
\hline \multirow[t]{2}{*}{ Milan } & $c_{e f}$ & 2.78 & 2.21 & & & & & & & & 4.99 & & & & 2.38 & & & \\
\hline & $T_{\text {diff }}\left[{ }^{\circ} \mathrm{C}\right]$ & $2.16^{*}$ & $1.06^{*}$ & & & & & & & & -2.53 & & & & $1.04 *$ & & & \\
\hline \multirow[t]{2}{*}{ Bologna } & & & & & & & & & & 10.39 & & & & & 1.99 & & & \\
\hline & $T_{\text {diff }}\left[{ }^{\circ} \mathrm{C}\right]$ & & & & & & & & & 1.23 & & & & & $1.31 *$ & & & \\
\hline \multirow[t]{2}{*}{ Hamburg } & $c_{e f}$ & 4.05 & & 4.67 & 3.09 & 5.08 & & & & & & & & & & & & \\
\hline & $T_{\text {diff }}\left[{ }^{\circ} \mathrm{C}\right]$ & $3.33 *$ & & $2.18 *$ & 1.50 & 1.86 & & & & & & & & & & & & \\
\hline \multirow[t]{2}{*}{ Bamberg } & $c_{e f}$ & 3.21 & 2.68 & 4.56 & & & & & & & & & & & & & & \\
\hline & $T_{\text {diff }}\left[{ }^{\circ} \mathrm{C}\right]$ & $3.56^{*}$ & $0.78^{*}$ & 0.25 & & & & & & & & & & & & & & \\
\hline Potsdam & $c_{e f}$ & 3.70 & & 2.71 & 6.15 & 4.42 & & 2.17 & & & & & & & & & & \\
\hline & $T_{\text {diff }}\left[{ }^{\circ} \mathrm{C}\right]$ & $3.82 *$ & & $1.59 *$ & 1.52 & 0.77 & & $-1.40 *$ & & & & & & & & & & \\
\hline Vestervig & $c_{e f}$ & & & 8.87 & 5.80 & 5.40 & 7.00 & & & & & & & & & & & \\
\hline & $T_{\text {diff }}\left[{ }^{\circ} \mathrm{C}\right]$ & & & $2.65 *$ & $2.32^{*}$ & 1.12 & -1.80 & & & & & & & & & & & \\
\hline Karlstad & $c_{e f}$ & 1.79 & & 6.10 & 4.17 & 3.41 & 3.76 & & & & & & 2.54 & & & & & \\
\hline & $T_{\text {diff }}\left[{ }^{\circ} \mathrm{C}\right]$ & $2.14 *$ & & $1.90 *$ & 0.72 & 1.32 & -1.88 & & & & & & $0.99 *$ & & & & & \\
\hline Stockholm & $c_{e f}$ & 2.08 & & 5.55 & 4.66 & & & & & & & & 2.26 & 2.46 & & & & \\
\hline & $T_{\text {diff }}\left[{ }^{\circ} \mathrm{C}\right]$ & $1.62 *$ & & $2.02 *$ & $1.88 *$ & & & & & & & & $1.14 *$ & 0.87 & & & & \\
\hline Prague & $c_{e f}$ & 2.06 & 2.26 & & 4.30 & 5.16 & & & & 4.66 & 5.27 & & & & & & & \\
\hline & $T_{\text {diff }\left[{ }^{\circ} \mathrm{C}\right]}$ & $3.63^{*}$ & $0.93^{*}$ & & $1.87^{*}$ & 0.54 & & & & $-1.85^{*}$ & -1.83 & & & & & & & \\
\hline Kremsmünster & $c_{e f}$ & 1.85 & 2.03 & & & & & 2.30 & & 5.32 & & & & & & & & \\
\hline & $T_{\text {diff }}\left[{ }^{\circ} \mathrm{C}\right]$ & $3.18^{*}$ & $0.99^{*}$ & & & & & -0.33 & & -0.63 & & & & & & & & \\
\hline Wien & $c_{e f}$ & & 1.92 & & & & & & 3.19 & 9.96 & 5.08 & & & & 1.82 & & & \\
\hline & $T_{\text {diff }}\left[{ }^{\circ} \mathrm{C}\right]$ & & $1.10^{*}$ & & & & & & $1.64 *$ & -0.56 & -3.21 & & & & $1.22 *$ & & & \\
\hline Zagreb & $c_{e f}$ & & & & & & & 2.84 & & 8.00 & & & & & & & & \\
\hline & $T_{\text {diff }}\left[{ }^{\circ} \mathrm{C}\right]$ & & & & & & & $0.85^{*}$ & & -0.04 & & & & & & & & \\
\hline Sarajevo & $c_{e f}$ & & & & & & & 4.90 & & 5.08 & & 3.17 & & & & & & \\
\hline & $T_{\text {diff }}\left[{ }^{\circ} \mathrm{C}\right]$ & & & & & & & $1.63^{*}$ & & -0.98 & & 0.40 & & & & & & \\
\hline Drobeta & $c_{e f}$ & & & & & & & 2.87 & & 6.54 & & 4.67 & & & & & & 2.56 \\
\hline & $T_{\text {diff }}\left[{ }^{\circ} \mathrm{C}\right]$ & & & & & & & $1.69 *$ & & -0.43 & & 0.69 & & & & & & $-1.85^{*}$ \\
\hline Bucuresti & $c_{e f}$ & & & & & & & 4.38 & & 3.70 & & 4.02 & & & & & & \\
\hline & $T_{\text {diff }}\left[{ }^{\circ} \mathrm{C}\right]$ & & & & & & & $1.50 *$ & & -0.79 & & 1.42 & & & & & & \\
\hline
\end{tabular}

Results for the CTs conducive to heat waves are summarized in Table 2.

Higher average temperature anomalies are typical on late compared to early stages of the central-European high types (HM and BM), which stems from both radiative and advective warming during a sequence of days with their occurrence. The differences are positive and statistically significant at all stations where these CTs are conducive to heat waves, except for Uccle and the BM type for which the difference is insignificant. Note that the radiative warming is effective due to a positive radiative balance under prevailing small total cloud amount and a lack of warm air removal (e.g. by atmospheric fronts) under high-pressure conditions; the advective warming stems from the prevailing eastward movement of synoptic formations in the mid-latitudes, with a cold/warm advection on the front/rear side of high pressure centres and ridges. Positive differences between temperature anomalies on late and early stages prevail for the east types conducive to heat waves (HFA, HNFA, HFZ and HNFZ), too, but they are mostly insignificant. For the south types conducive to heat waves, which are often associated with trough over western Europe and approaching atmospheric fronts and prefrontal convective systems, negative but mostly insignificant differences prevail; however, significant positive differences appear more often than significant negative ones.

The differences in temperature anomalies between the late and early stages of the CTs are significantly positive for 43 station-CT pairs while significantly negative for 5 pairs only (if all stations and the CTs conducive to heat waves are taken together). It is obvious that more persistent atmospheric cir- 

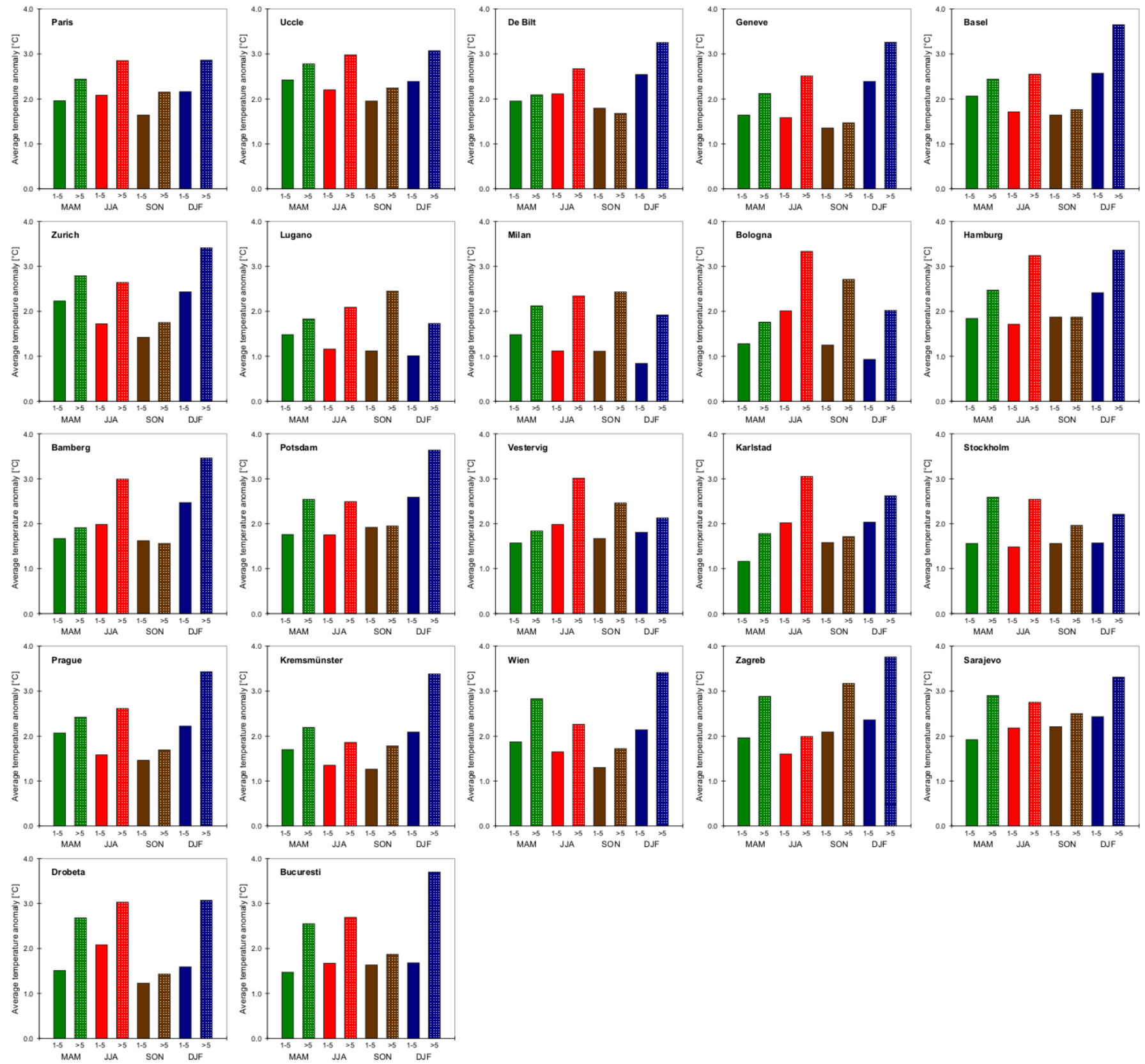

Fig. 3. Average temperature anomalies on early (days 1-5) and late stages (days $>5$ ) of warm circulation types (CTs) in individual seasons. Warm CTs are defined as types with temperature anomalies averaged over all days of their occurrence in a given season $\geq 1.0^{\circ} \mathrm{C}$.

culation supports more severe and longer heat waves since most CTs significantly conducive to heat waves are warmer on late stages (days $>5$ ) of their persistent occurrences.

\subsection{Overall temperature differences between late and early stages of warm CTs in all seasons}

The results presented in Sect. 3.2 were confined to the CTs significantly conducive to heat waves in JJA; general differences between late and early stages of CTs are examined in this section for all "warm" CTs (defined as types with a temperature anomaly averaged over all days of their occurrence in a given season $\geq 1.0^{\circ} \mathrm{C}$ ), separately in individual seasons (MAM, JJA, SON and DJF).

Figure 3 shows the overall tendency of warm CTs to be warmer on late than early stages, which is observed at all sites in all seasons except for 3 stations (De Bilt, Bamberg and Hamburg) in SON. The differences between late and early stages of the warm CTs are largest in DJF and JJA, 
reaching on average $1.0^{\circ} \mathrm{C}$ in DJF and $0.9^{\circ} \mathrm{C}$ in JJA; while the mean temperature anomaly in warm CTs (averaged over the stations) on days $1-5$ is $+2.0^{\circ} \mathrm{C}$ in $\mathrm{DJF}$ and $+1.8^{\circ} \mathrm{C}$ in JJA, on days $>5$ it makes $+3.0^{\circ} \mathrm{C}$ in DJF and $+2.7^{\circ} \mathrm{C}$ in JJA. In transition seasons, the differences between late and early stages of the warm CTs are smaller $\left(0.6^{\circ} \mathrm{C}\right.$ in MAM and $0.4^{\circ} \mathrm{C}$ in SON averaged over the stations) which is likely related to less clear links between circulation patterns and surface temperature anomalies in spring and autumn (e.g. the central-European high types and east types tend to be associated with positive/negative temperature anomalies in early/late autumn).

The results show that the general tendency observed at all stations over the examined area would be towards an increase in the severity of warm anomalies under more persistent weather conditions (in all seasons but more importantly in DJF and JJA than in MAM and SON).

\section{Conclusions}

Mean air temperature anomalies at stations over large parts of the European continent were examined on early and late stages of occurrences of atmospheric circulation patterns conducive to summer heat waves. A similar analysis was carried out also for "warm" CTs (associated with mean temperature anomalies in a given season $\geq 1.0^{\circ} \mathrm{C}$ ) throughout year.

It has been shown that during late stages of persistent CTs conducive to summer heat waves, positive temperature anomalies tend to be more pronounced. The effect is particularly strong for the central-European high types and east types, and results from both positive radiative balance and warm advection during late stages of their occurrences. Although some differences among sites as well as groups of CTs appear, the general pattern prevails over all parts of Europe.

Positive differences between mean temperature anomalies on late and early stages of CTs are observed for warm CTs generally in all seasons; days $>5$ are warmer than days $1-5$ on average by $0.6^{\circ} \mathrm{C}$ in MAM, $0.9^{\circ} \mathrm{C}$ in JJA, $0.4^{\circ} \mathrm{C}$ in SON, and $1.0^{\circ} \mathrm{C}$ in DJF. Again, the pattern is universal over Europe.

The findings support a hypothesis that recent rising trends in temperature extremes (e.g. Klein Tank and Koennen, 2003; Domonkos et al., 2003; Moberg et al., 2006) and the frequency and severity of heat waves over Europe (e.g. Beniston, 2004; Della-Marta et al., 2007) might to some extent be related to greater residence times of circulation patterns conducive to positive temperature anomalies. The possibility of increasing severity of heat waves over Europe due to circulation changes is particularly opportune within the "global warming" perspective, since a decreased cyclone density over the mid-latitudes and a northward shift of the North Atlantic storm track have been projected as likely future scenarios in a number of climate change modelling studies (e.g. Knippertz et al., 2000; Geng and Sugi, 2003; Bengtsson et al., 2006; Leckebusch et al., 2006). This would sup- port more persistent circulation patterns over western and central Europe, and impacts of the climate change on the occurrence of heat waves might be exacerbated. If similar changes towards enhanced persistence of CTs occur in other mid-latitudinal regions, analogous consequences and implications for changes in the severity of temperature extremes are expected.

Acknowledgements. Thanks are due to T. Schlegel, MeteoSwiss, for homogenized temperature data from Swiss stations; F.-W. Gerstengarbe, Potsdam Institute for Climate Impact Research, for the revised dataset of the Hess-Brezowsky Grosswetterlagen; and J. Moliba, Institute of Atmospheric Physics Prague, for assistance in preparing temperature datasets. The research was supported by the Czech Science Foundation under project 205/07/J044.

Edited by: P. Lagos

Reviewed by: two anonymous referees

\section{References}

Begert, M., Schlegel, T., and Kirchhofer, W.: Homogeneous temperature and precipitation series of Switzerland from 1864 to 2000, Int. J. Climatol., 25, 65-80, 2005.

Bengtsson, L., Hodges, K. I., and Roeckner, E.: Storm tracks and climate change, J. Climate, 19, 3518-3543, 2006.

Beniston, M.: The 2003 heat wave in Europe: A shape of things to come? An analysis based on Swiss climatological data and model simulations, Geophys. Res. Lett., 31, L02202, doi:10.1029/2003GL018857, 2004.

Camuffo, D. and Jones, P.: Improved understanding of past climatic variability from early daily European instrumental sources, Kluwer Academic Publishers, Dordrecht, Boston, London, 392 pp., 2002.

Cawley, G. C.: Mean daily surface level pressure anomaly charts by Grosswetterlagen Index, University of East Anglia, Norwich, UK, available at http://theoval.sys.uea.ac.uk/ gcc/ projects/accord/experiments/experimentla/report.html, 2002.

Della-Marta, P. M., Luterbacher, J., von Weissenfluh, H., Xoplaki, E., Brunet, M., and Wanner, H.: Summer heat waves over western Europe 1880-2003, their relationship to large-scale forcings and predictability, Clim. Dynam., 29, 251-275, 2007.

Domonkos, P., Kyselý, J., Piotrowicz, K., Petrovic, P., and Likso, T.: Variability of extreme temperature events in south-central Europe during the 20th century and its relationship with large scale circulation, Int. J. Climatol., 23, 987-1010, 2003.

Filleul, L., Cassadou, S., Medina, S., Fabres, P., Lefranc, A., Eilstein, D., Le Tertre, A., Pascal, L., Chardon, B., Blanchard, M., Declercq, C., Jusot, J. F., Prouvost, H., and Ledrans, M.: The relation between temperature, ozone, and mortality in nine French cities during the heat wave of 2003, Env. Health Persp., 114, 1344-1347, 2006.

Geng, Q. and Sugi, M.: Possible change of extratropical cyclone activity due to enhanced greenhouse gases and sulfate aerosols study with a high-resolution AGCM, J. Climate, 16, 2262-2274, 2003.

Gerstengarbe, F.-W., Werner, P. C., and Rüge, U.: Katalog der Grosswetterlagen Europas nach Paul Hess und Helmuth Bre- 
zowsky 1881-1998, Deutscher Wetterdienst, Offenbach a. Main, 1999.

Grize, L., Huss, A., Thommen, O., Schindler, C., and BraunFabrlander, C.: Heat wave 2003 and mortality in Switzerland, Swiss Med. Weekly, 135, 200-205, 2005.

Hess, P. and Brezowsky, H.: Katalog der Grosswetterlagen Europas, Ber. Dt. Wetterdienstes in der US-Zone, Nr. 33, 39 pp., 1952.

Klein Tank, A. M. G., Wijngaard, J. B., Koennen, G. P., and coauthors: Daily dataset of 20th century surface air temperature and precipitation series for the European Climate Assessment, Int. J. Climatol., 22, 1441-1453, 2002.

Klein Tank, A. M. G. and Koennen, G. P.: Trends in indices of daily temperature and precipitation extremes in Europe, 1946-99, J. Climate, 16, 3665-3680, 2003.

Knippertz, P., Ulbrich, U., and Speth, P.: Changing cyclones and surface wind speeds over the North Atlantic and Europe in a transient GHG experiment, Clim. Res., 15, 109-122, 2000.

Kyselý, J.: Temporal fluctuations in heat waves at PragueKlementinum, the Czech Republic, from 1901-1997, and their relationships to atmospheric circulation, Int. J. Climatol., 22, 3350, 2002.

Kyselý, J.: Implications of enhanced persistence of atmospheric circulation for the occurrence and severity of temperature extremes, Int. J. Climatol., 27, 689-695, 2007.

Kyselý, J. and Domonkos P.: Recent increase in persistence of atmospheric circulation over Europe: Comparison with long-term variations since 1881, Int. J. Climatol., 26, 461-483, 2006.

Kyselý, J. and Dubrovský, M.: Simulation of extreme temperature events by a stochastic weather generator: Effects of interdiurnal and interannual variability reproduction, Int. J. Climatol., 25, 251-269, 2005.
Leckebusch, G. C., Koffi, B., Ulbrich, U., Pinto, J. G., Spangehl, T., and Zacharias, S.: Analysis of frequency and intensity of European winter storm events from a multi-model perspective, at synoptic and regional scales, Clim. Res., 31, 59-74, 2006.

Moberg, A. and Jones, P. D.: Trends in indices for extremes in daily temperature and precipitation in central and western Europe, 1901-99, Int. J. Climatol., 25, 1149-1171, 2005.

Moberg, A., Jones, P. D., Lister, D., and co-authors: Indices for daily temperature and precipitation extremes in Europe analyzed for the period 1901-2000, J. Geophys. Res., 111, D22106, doi:10.1029/2006JD007103, 2006.

Poumadere, M., Mays, C., Le Mer, S., and Blong, R.: The 2003 heat wave in France: Dangerous climate here and now, Risk Analysis, 25, 1483-1494, 2006.

Schär, C., Vidale, P. L., Lüthi, D., Frei, C., Häberli, C., Liniger, M. A., and Appenzeller, C.: The role of increasing temperature variability in European summer heatwaves, Nature, 427, 332336, 2004.

Sheridan, S. C. and Kalkstein, L. S.: Progress in heat watchwarning system technology, B. Am. Meteorol. Soc., 85, 19311941, 2004.

Werner, P. C., Gerstengarbe, F.-W., Fraedrich, K., and Oesterle, H.: Recent climate change in the North Atlantic/European sector, Int. J. Climatol., 20, 463-471, 2000.

Wijngaard, J. B., Klein Tank, A. M. G., and Koennen, G. P.: Homogeneity of 20th century European daily temperature and precipitation series, Int. J. Climatol., 23, 679-692, 2003. 